Journal of Clinical Investigation

Vol. 42, No. 5, 1963

\title{
THE INFLUENCE OF HEART RATE ON LEFT VENTRICULAR VOLUME IN DOGS *
}

\author{
BY J. DAVID BRISTOW, $\dagger$ RICHARD E. FERGUSON, $\ddagger$ FREDRIC MINTZ,§ AND \\ ELLIOT RAPAPORT
}

\author{
(From the Cardiovascular Research Institute and the Department of Medicine, University of \\ California School of Medicine, and the Cardiopulmonary Laboratory, San \\ Francisco, General Hospital, San Francisco, Calif.)
}

(Submitted for publication August 10, 1962; accepted January 17, 1963)

The effects of changes in heart rate must be understood before ventricular performance can be evaluated in studies of the response to drugs, injury, or abnormal circulatory states. This report describes the effects of sudden changes in heart rate on the stroke, end-systolic, and enddiastolic volume of the canine left ventricle. The ventricular volumes were measured by thermodilution, an indicator dilution method in which injected cold blood serves as the indicator (1).

\section{METHODS}

There were 160 experimental periods in 11 mongrel dogs that were anesthetized with a chloralose-urethane mixture. Aortic thermodilution curves were obtained after rapid injection of cooled autologous blood into the left ventricle. A $4 \mathrm{~F}$ catheter with an ultrasmall bead thermistor secured to its end ${ }^{1}$ was used to record blood temperature. It was introduced into a carotid artery and advanced so that its tip was just above the aortic valve. The time constant of this assembly was $0.12 \mathrm{sec}-$ ond when tested in slowly flowing water. A 7F catheter with multiple side holes and a closed end was manipulated into the left ventricle from a femoral artery for injection purposes and to record left ventricular pressure with a strain gauge. A bead thermistor was secured within its lumen near the tip to monitor the temperature of the injected blood immediately before it entered the left ventricle. This assembly had a time constant of 0.05 second in flowing water.

* Supported by U. S. Public Health Service grants $\mathrm{H}-6285$ and $\mathrm{H}-5817$ and a grant from the San Mateo County Heart Association.

$\dagger$ Work performed during the tenure of a special fellowship of the U. S. Public Health Service (HF-13,456).

$\$$ Work performed during the tenure of a postdoctoral fellowship of the L. S. Public Health Service (HF-14,505 ).

$\S$ Work performed during the tenure of a postdoctoral fellowship of the U. S. Public Health Service (HF14,451).

1 Victory Engineering Corp., Union, N. J.
Injections were made with a metal syringe driven by compressed air that introduced a known amount, usually 3 to $5 \mathrm{ml}$, of cooled, heparinized, autologous blood into the left ventricle in less than 0.5 second. The mean temperature of the injected blood was determined by planimetry of the recorded temperature curve during injection. Stroke volume $(S V)$, end-systolic volume $(E S V)$, and end-diastolic volume $(E D V)$ were calculated from the resultant aortic thermodilution curve sensed by the aortic thermistor catheter. The formulas used. to calculate these volumes were:

$$
S V(\mathrm{ml})=\frac{V_{i}\left(T_{b}-T_{i}\right)}{\Sigma\left(\Delta T_{b}\right)},
$$

where $V_{i}=$ volume of injected cooled blood in $\mathrm{ml}, T_{b}$ $=$ left ventricular blood temperature before injection, $T_{i}$ $=$ mean temperature of injected blood, just before it entered the left ventricle, and $\Sigma\left(\Delta T_{b}\right)=$ the sum of the differences between base-line aortic temperature and that resulting in the aorta from each systole, as measured at end-diastole;

2)

$$
E S V / E D V=\frac{\Delta T_{n+1}}{\Delta T_{n}},
$$

where $\Delta T_{n}$ and $\Delta T_{n+1}$ are differences between base-line aortic temperature and that at beats $n$ and $n+1$, respectively, measured at end-diastole from the exponential step-function of the aortic thermodilution curve;

$$
\text { 3) } \begin{aligned}
& E D V(\mathrm{ml})=\frac{S V}{1-\frac{E S V}{E D V}} ; \\
& E S V(\mathrm{ml})=E D V-S V ;
\end{aligned}
$$

and

5) Cardiac output $(\mathrm{L} / \mathrm{min})=\frac{(\text { heart rate })(S V)}{1,000}$.

The details of this method have been published previously (1).

One to five determinations of left ventricular volumes, left ventricular pressure, and heart rate were made during each control and experimental period. Various heart rates faster than control were produced with a $6 \mathrm{~F}$ electrode catheter passed up a femoral vein and placed fluoroscopically against the right atrial appendage. The other electrode was on the right chest wall. Pacing was 
achieved with a stimulus of 1 to $5 \mathrm{v}$ lasting $10 \mathrm{msec}$ as provided by a Grass model S4DR stimulator. The different rates at which the hearts were paced were randomly chosen, and control measurements were repeated after each new rate change. The effects of pacing per se were studied in six experimental periods in different animals when the pacing rate was within 2 beats per minute of the heart rate present at the onset of pacing. The average $E S V / E D V$ ratio (in per cent) for these six pairs of observations was $73 \%$ before and $72 \%$ after pacing was established. Stroke volume was an average of $16.3 \mathrm{ml}$ both before and with pacing.

Heart rates slower than control were produced by stimulating the peripheral end of the right vagus nerve which had been severed in the neck. Usually, an electrical pulse of $10 \mathrm{c}$ per second and 1 ma produced bradycardia. If the heart rate became irregular at the slow rate, or if ventricular standstill occurred, a constant slow rate was obtained by simultaneously pacing the right atrial electrode catheter with a rate somewhat faster than that resulting from vagal stimulation alone. Only curves that were associated with a regular rhythm were analyzed.

The two basic measurements made with the thermodilution curves were $S V$ and the $E S V / E D V$ ratio, as shown in Formulas 1 and 2. The ratio $E S V / E D V$ is probably the more accurate of the two, since it is not dependent upon an exact amount of injected indicator. It represents the degree of emptying characteristic of the ventricle at the time, and is the proportion of the $E D V$ that remains in the ventricle at the end of systole. In order to assess the reproducibility of the results in this study, 20 experimental periods were chosen randomly from several animals. During each, two or three thermo- dilution curves had been obtained, with a total of 44 curves. The variations of $S V$ and $E S V / E D V$ for repeat determinations within an experimental period were expressed as a percentage difference from the average for that period, regardless of sign. The mean variation for $E S V / E D V$ from the average for any experimental period was $3.4 \pm 3.3 \% \quad($ mean $\pm 1 \quad \mathrm{SD})$. This agrees closely with our previous observations on the reproducibility of the method (1). Stroke volume variations from the average within an experimental period were $8.2 \pm$ $7.1 \%$.

In early experiments with thermodilution, we compared the cardiac outputs obtained by Evans blue dye and thermodilution following left ventricular injection of cold Evans blue dye. The ratio of outputs calculated from thermodilution curves to dye dilution outputs averaged 1.09 ( $\mathrm{SD}, .12)$. We believe that this reasonable standard deviation has been further reduced by subsequent improvements in our technique, including the substitution of the animal's own cooled blood for saline as the injection (eliminating the problems of specific heat capacity and specific gravity) and more accurate registration of the injection temperature.

The $E S V / E D V$ ratio and all of the volume calculations depend on an exponential washout of indicator from the left ventricle. In routine analysis of the thermodilution curves, the series of beat to beat downslope temperature ratios, $T_{3} / T_{2}, T_{4} / T_{3}, T_{5} / T_{4}$, and so forth, were averaged to obtain the $E S V / E D V$ ratio for that curve. To test the variability of the downslope exponential functions we observed, 46 randomly chosen curves from similarly conducted previous experiments were analyzed in more detail. The variation of each $T_{n+1} / T_{n}$ ratio in the downslope was compared to the average of such ratios for a

TABLE I

Original control measurements in all animals*

\begin{tabular}{|c|c|c|c|c|c|c|c|c|}
\hline Dog & Weight & $\begin{array}{c}\text { Heart } \\
\text { rate }\end{array}$ & $\begin{array}{l}\text { Cardiac } \\
\text { output }\end{array}$ & $\begin{array}{l}\text { Stroke } \\
\text { volume }\end{array}$ & $\begin{array}{l}\text { End- } \\
\text { diastolic } \\
\text { volume }\end{array}$ & $\begin{array}{l}\text { End- } \\
\text { systolic } \\
\text { volume }\end{array}$ & $E S V / E D V$ & $\begin{array}{c}\text { Left } \\
\text { ventricular } \\
\text { systolic } \\
\text { pressure }\end{array}$ \\
\hline & $\mathrm{kg}$ & beats/min & $L / \min$ & $m l$ & $m l$ & $m l$ & $\%$ & $m m \mathrm{Hg}$ \\
\hline 1 & 17.7 & 135 & 1.37 & 9.9 & 39.6 & 29.7 & 74 & 166 \\
\hline 2 & 18.6 & 167 & 1.85 & 11.3 & 43.5 & 32.2 & 74 & 184 \\
\hline 3 & 20.5 & 199 & 2.87 & 14.6 & 37.4 & 22.8 & 61 & 185 \\
\hline 4 & 15.9 & 151 & 1.57 & 10.7 & 34.0 & 23.3 & 66 & 213 \\
\hline 5 & 19.1 & 121 & 1.22 & 10.0 & 47.6 & 37.6 & 79 & 177 \\
\hline 6 & 34.1 & 152 & 1.28 & 8.4 & 26.9 & 18.6 & 69 & 153 \\
\hline 7 & 29.5 & 157 & 3.40 & 21.7 & 67.8 & 46.2 & 68 & 203 \\
\hline 8 & 29.5 & 112 & 2.19 & 19.4 & 59.8 & 40.4 & 68 & 161 \\
\hline 9 & 21.8 & 86 & 3.41 & 39.7 & 110.5 & 70.8 & 64 & 189 \\
\hline 10 & 23.6 & 126 & 1.08 & 8.7 & 35.5 & 26.9 & 76 & 165 \\
\hline 11 & 24.1 & 112 & 1.68 & 14.6 & 51.7 & 37.2 & 72 & 213 \\
\hline Mean & 23.1 & 138 & 1.99 & 15.4 & 50.4 & 35.1 & 70.1 & 183 \\
\hline SD & & 31.3 & 0.86 & 9.2 & 23.2 & 14.5 & 5.4 & 20.7 \\
\hline
\end{tabular}

* Each value listed for each animal is an average of all measurements during the first control period of the experiment. Heart rate was measured from records of left ventricular pressure as well as the thermodilution curves. Thus the product of rate and stroke volume as listed above may not exactly equal the cardiac output in the table. In experiments 1 and 4 , several thermodilution curves were obtained for estimating the $E S V / E D V$ ratio besides those used to measure the actual volumes. 
TABLE II

Effect of changes in heart rate on cardiac output and left ventricular volumes

\begin{tabular}{|c|c|c|c|c|c|}
\hline $\begin{array}{l}\text { Heart } \\
\text { rate* }\end{array}$ & $\begin{array}{l}\text { Observa- } \\
\text { tions }\end{array}$ & Cardiac output & Stroke volume & $\begin{array}{l}\text { End-diastolic } \\
\text { volume }\end{array}$ & $\begin{array}{c}\text { End-systolic } \\
\text { volume }\end{array}$ \\
\hline$\%$ & no. & $\%$ & $\%$ & $\%$ & $\%$ \\
\hline $40-59$ & 16 & $82.2 \pm 56.5$ & $158.5 \pm 99.0$ & $133.3 \pm 81.9$ & $122.1 \pm 75.6$ \\
\hline $60-79$ & 10 & $86.4 \pm 31.8$ & $132.2 \pm 48.8$ & $99.8 \pm 29.0$ & $86.4 \pm 24.5$ \\
\hline $80-99$ & 22 & $93.0 \pm 29.8$ & $100.5 \pm 29.0$ & $93.9 \pm 30.0$ & $90.4 \pm 35.1$ \\
\hline $100-119$ & 46 & $106.7 \pm 30.2$ & $99.0 \pm 27.0$ & $93.7 \pm 23.4$ & $91.3 \pm 24.7$ \\
\hline $120-139$ & 20 & $117.3 \pm 29.2$ & $92.8 \pm 22.5$ & $90.6 \pm 23.6$ & $90.1 \pm 27.3$ \\
\hline $140-159$ & 12 & $103.3 \pm 25.5$ & $64.4 \pm 21.6$ & $65.3 \pm 21.6$ & $65.8 \pm 23.0$ \\
\hline $160-179$ & 10 & $108.4 \pm 25.0$ & $64.4 \pm 14.5$ & $63.7 \pm 15.3$ & $64.1 \pm 17.3$ \\
\hline $180-260$ & 13 & $94.7 \pm 29.6$ & $47.7 \pm 17.0$ & $58.2 \pm 16.6$ & $63.0 \pm 18.4$ \\
\hline
\end{tabular}

* In order to compare different animals and to pool the results for statistical analysis, all values after the original control measurements were expressed as percentages of these original controls. These include observations during normal rhythm between periods of pacing or induced bradycardia. Means $\pm 1 \mathrm{SD}$ are listed.

given curve. The difference from the average was expressed as a percentage. For 156 ratios in these 46 curves, the mean deviation from the average was $4.9 \pm 3.8 \%$.

\section{RESULTS}

The results are listed in Tables I to IV. After the original control observations in each animal,

$\checkmark$ all subsequent measurements of heart rate, cardiac output, and ventricular volumes were expressed as percentages of the original control values. The $E S V / E D V$ ratios were always expressed as absolute values $(E S V / E D V \times 100=\%)$, in order to avoid the confusion which would have resulted from the use of a proportion of a ratio.

There were no significant differences between the values found at 80 to $99 \%$ and 100 to $119 \%$ of the original rates. These results occurred for the most part during periods of normal rhythm between runs of electrical pacing or induced bradycardia. For statistical comparison with faster and slower rates, the results between 80 and $119 \%$ of the original heart rates were pooled as a control group. Comparison with other rate groups was made by the $t$ test. Significant findings were considered present when the probability value found was less than 0.05 .

Tachycardia above $140 \%$ of control caused a significant decrease in $S V$. The $S V$ at the fastest rates ( $>180 \%$ of control) fell to less than half of the original values. Bradycardia below $80 \%$ of control was associated with an increased $S V$, which at the slowest rates increased by a mean value of $58.5 \%$.

The changes in $E S V$ and $E D V$ paralleled those of $S V$, but were less marked. With extreme tachycardia the $E D V$ was $58 \%$ of control. At the slowest rates, a mean value for $E D V$ of $133 \%$ was found, but was not shown to be statistically different from control at the 0.05 probability level. Generally similar changes were found with the $E S V$.

TABLE III

Probability values from comparison of pooled results at rates of 80 to $119 \%$ of the original controls with faster and slower rates $^{*}$

\begin{tabular}{ccccc}
\hline \hline $\begin{array}{c}\text { Heart } \\
\text { rate } \\
\text { (\% of } \\
\text { original) }\end{array}$ & $\begin{array}{c}\text { Cardiac } \\
\text { output } \\
\mathrm{p}\end{array}$ & $\begin{array}{c}\text { Stroke } \\
\text { volume } \\
\mathrm{p}\end{array}$ & $\begin{array}{c}\text { End- } \\
\text { diastolic } \\
\text { volume } \\
\mathrm{p}\end{array}$ & $\begin{array}{c}\text { End- } \\
\text { systolic } \\
\text { volume } \\
\mathrm{p}\end{array}$ \\
\hline $\begin{array}{c}40-59 \\
60-79\end{array}$ & $<0.025$ & & \\
$120-139$ & $<0.050$ & $<0.050$ & & \\
$140-159$ & & $<0.001$ & $<0.001$ & $<0.005$ \\
$160-179$ & & $<0.001$ & $<0.001$ & $<0.001$ \\
$180-260$ & & $<0.001$ & $<0.001$ & $<0.001$ \\
\hline
\end{tabular}

TABLE IV

End-systolic volume to end-diastolic volume ratios for all experiments*

\begin{tabular}{|c|c|c|c|}
\hline $\begin{array}{c}\text { Heart } \\
\text { rate } \\
\text { (\% of } \\
\text { original) }\end{array}$ & $\begin{array}{l}\text { Obser- } \\
\text { vations }\end{array}$ & $E S V / E D V$ & $\begin{array}{l}\text { Probability values } \\
\text { from comparison with } \\
\text { pooled control group }\end{array}$ \\
\hline & no. & $\%$ & $p$ \\
\hline $40-59$ & 16 & $62.6 \pm 7.1$ & $<0.020$ \\
\hline $60-79$ & 10 & $62.4 \pm 6.9$ & $<0.050$ \\
\hline $80-99$ & 22 & $65.4 \pm 5.8\}$ & \multirow{2}{*}{ Pooled control group } \\
\hline $100-119$ & 57 & $67.9 \pm 6.0\}$ & \\
\hline $120-139$ & 20 & $71.8 \pm 7.2$ & $<0.010$ \\
\hline $140-159$ & 12 & $71.0 \pm 5.5$ & $<0.050$ \\
\hline $160-179$ & 10 & $74.1 \pm 4.2$ & $<0.001$ \\
\hline $180-260$ & 13 & $76.4 \pm 5.0$ & $<0.001$ \\
\hline
\end{tabular}

* There was no difference between the groups which were 80 to $99 \%$ and 100 to $119 \%$ of the original control rates. These two groups were pooled for statistical comparison with other rate groups. The origina 11 control observation 
It decreased significantly with fast rates, but was not proven statistically to have increased with bradycardia.

The mean ratio of $E S V$ to $E D V$ during the first control periods was $70.1 \%$ (SD, $5.4 \%)$ and is in agreement with other control observations from our laboratory for the dog anesthetized with chloralose and urethane (2). At rates above $120 \%$ of

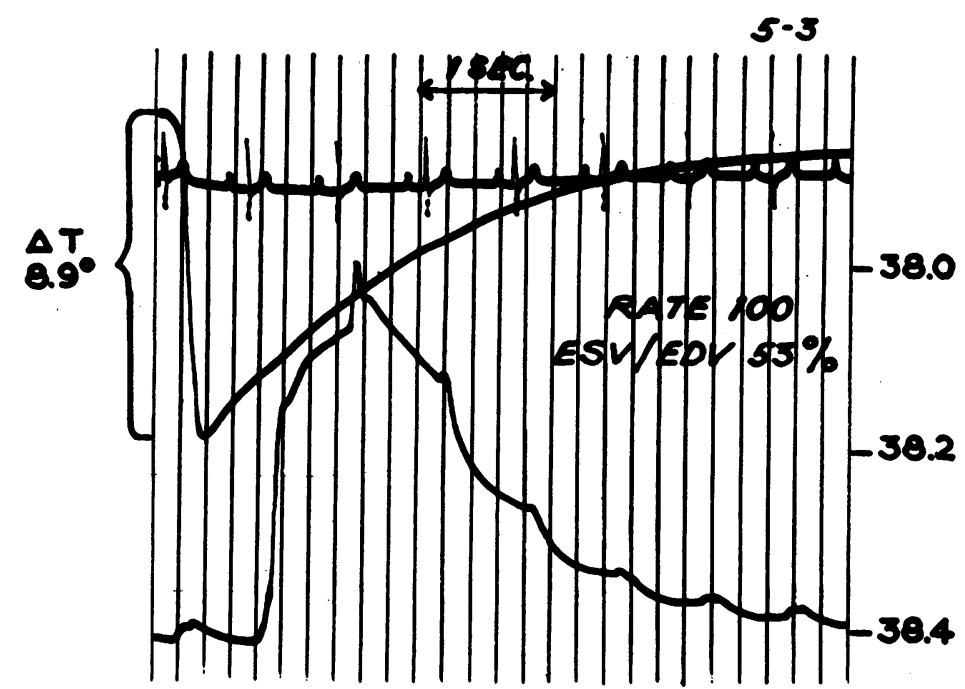

A.

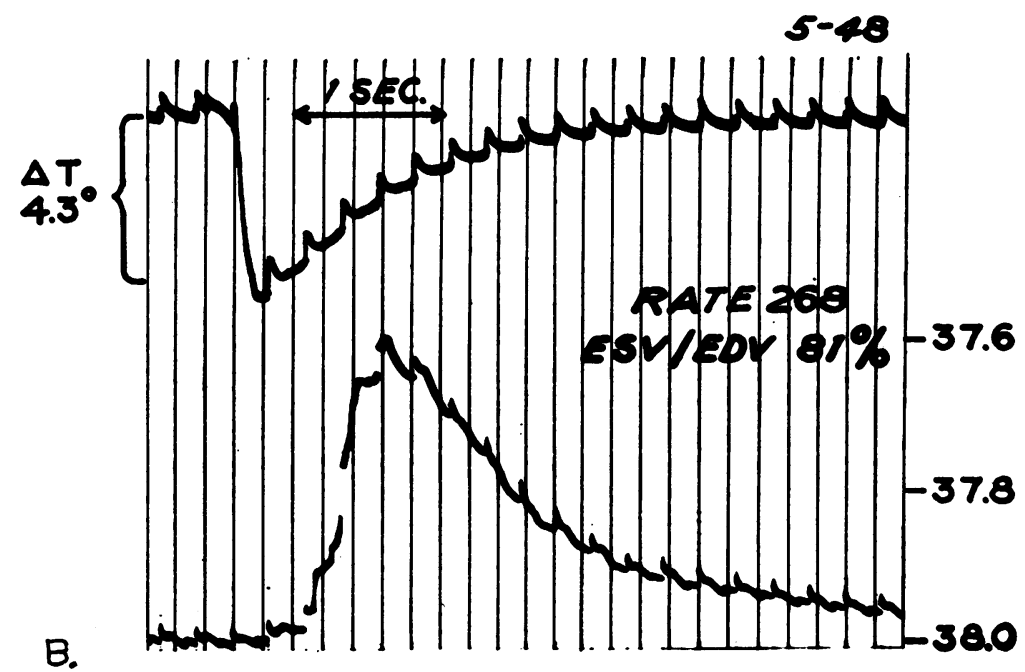

FIG. 1, A AND B. THE EFFECTS OF EXTREME TACHYCARDIA ON THE RATIO OF END-SYSTOLIC VOLUME (ESV) TO END-DIASTOLIC VoluME (EDV). In both examples the upper curve is the record of the temperature of the injected cooled blood, and a downward deflection indicates a lower temperature. $\Delta T$ is the difference between left ventricular blood temperature before injection and the peak coldness of the injected blood. At the bottom is the aortic thermodilution curve. The temperature scale on the right applies to it, and an upward deflection results from lowered temperature. The height above the base line of each diastolic plateau on the downslope of the aortic curve, divided by the height of the preceding one, equals the ratio of $E S V$ to $E D V$. A. With a spontaneous rate of 100 , the $E S V$ was $53 \%$ of the $E D V$. B. When paced at 268 per minute, the $E S V / E D V$ was $81 \%$, and the stroke volume $(S V)$, therefore, was only $19 \%$ of the $E D V$. 


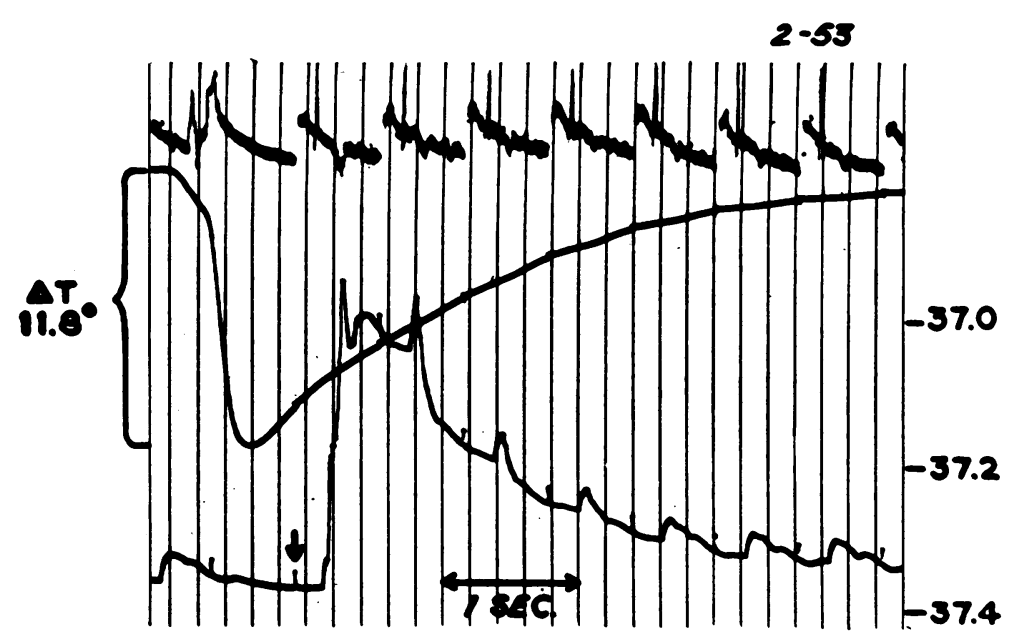

Fig. 2. VAgal stimulation and pacing. When the rate was slowed to 100 , the $E S V / E D V$ was $64 \%$, a typical value at this rate. The artifact from the electronic pacemaker is shown by the arrow.

control, this residual fraction increased and became progressively larger with more extreme tachycardia (Figure 1 and Table IV). The opposite was observed with bradycardia (Figure 2). The mean values for $S V, E D V$, and $E S V$ are plotted in Figure 3, and further illustrate the manner in which the $E S V$ to $E D V$ ratios changed.

At the two extremes of rate, cardiac output did not change significantly, since opposite changes in $S V$ counterbalanced the rate changes. With rates only slightly faster than control (120 to $139 \%$ ), cardiac output rose $17 \%$, which was a significant change. This resulted from an increased rate and an unchanged $S V$.

\section{DISCUSSION}

Rushmer noted that the change in diameter of the dog's left ventricle caused by each stroke output decreased as the heart rate was increased by right atrial electrode pacing (3). Warner and Toronto (4) and Miller and his colleagues (5) also demonstrated a progressive fall in $S V$ as pacing increased the ventricular rate in dogs with surgically produced complete heart block. Our results agree with these observations at the extremes of rate change. Between 80 and $140 \%$ of control rates, however, there was no significant change in $S V$. Consequently, cardiac output rose

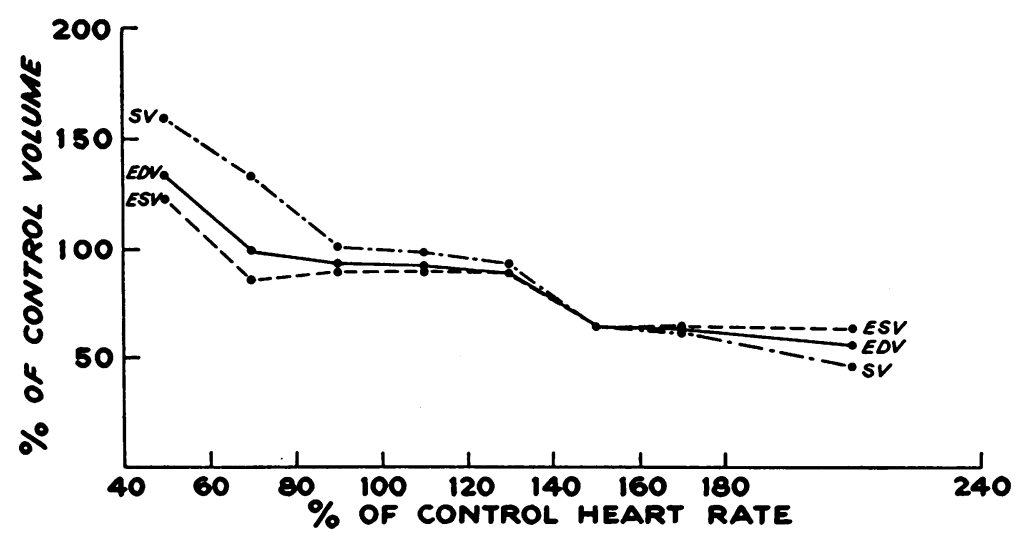

Fig. 3. The mean values for SV, EDV, and ESV are plotted in the MIDDLE OF EACH RATE GROUP. $S V$ shows the greatest change over the entire range of rates, and $E S V$ the least. 


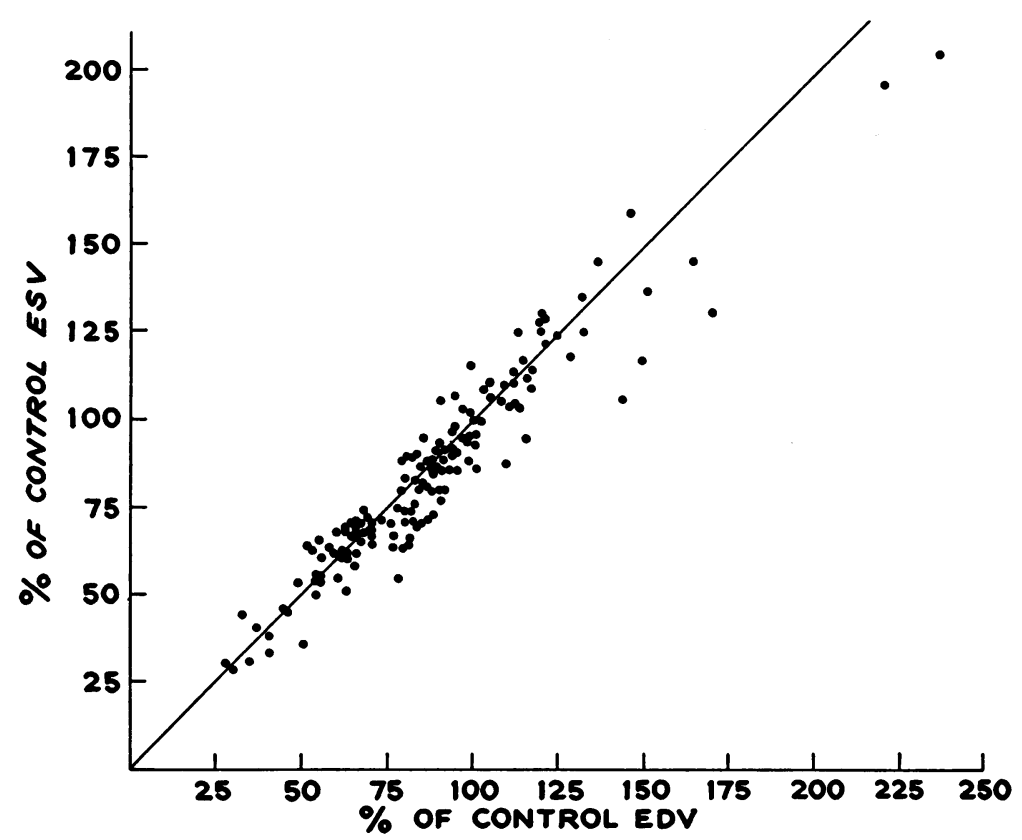

Fig. 4. The relation between ESV, and EDV is illustrated. The plot as percentage of control volumes suggests that these two volumes changed in proportion to each other. Individual animals, however, had lesser changes in $E S V$ than in $E D V$ at the extremes of rate change.

slightly but significantly with rates 20 to $40 \%$ above control levels.

These observations provide an interesting contrast with studies which have shown that $S V$ does not fall with the tachycardia of exercise, even at rates faster than those in our study $(6-8)$. The exercise response of stroke volume to tachycardia differs from the results of electrical pacing, although the $E D V$ becomes smaller in both situations. Diastolic filling time is shorter in both circumstances and cannot account for the difference. If arterial blood pressure has not decreased, the maintenance of a normal $S V$, despite a smaller $E D V$ during exercise, implies that there are mechanisms to increase ventricular emptying as well as to maintain an adequate venus return. With fast pacing in our experiments, opposite effects were observed, with decreased stroke volume and proportionately decreased ventricular emptying (higher $E S V / E D V$ ).

Previous studies have shown a generally linear relationship between the $E S V$ and the $E D V(2,9$, 10). This was observed again in this study over the wide range of heart rates produced (Figure
4). A small $E S V$ at fast rates was usually associated with a small $E D V$, whereas a larger $E S V$ was associated with a larger $E D V$ at slower rates. Since the plot of all of the experimental values in Figure 4 represents percentage of change from each individual animal's own control values, the distribution appears to pass through the origin. However, a linear regression equation of the absolute values does not pass through the origin. This is in keeping with the fact that values from individual animals consistently indicated a higher $E S V / E D V$ with tachycardia and the opposite with bradycardia. Thus, EDV fell more than $E S V$ at fast rates, and the ventricle emptied actually and proportionately less. At slow rates, ventricular emptying was proportionately greater, despite a larger $E S V$, since a greater part of the $E D V$ was ejected with systole. These findings support a concept that the left ventricle does not function with a relatively constant end-systolic or residual volume over a wide range of end-diastolic volumes. Rather, within the conditions of these experiments, the changes in the ventricular volumes were in the same direction but varied in 
degree. Stroke volume was influenced the most, and the $E S V$ the least by a given alteration in rate.

\section{SUM MARY}

The effects of sudden changes in heart rate on left ventricular volumes were studied in dogs. Fast rates were produced by electrical pacing and slow rates by efferent stimulation of the right vagus nerve, with and without slow pacing. The left ventricular stroke and the end-systolic and end-diastolic volumes were measured by an indicator dilution method in which temperature was the indicator. Cooled blood was injected into the ventricle, and aortic thermodilution curves were recorded by a thermistor catheter.

The left ventricular volumes decreased during moderate tachycardia. At the fastest rates produced, the fall in stroke volume was proportionately greater than that in end-systolic and enddiastolic volumes. At slow rates, stroke volume increased proportionately more than the other two volumes.

The findings indicate that the left ventricle in these experiments did not function with a constant end-systolic or residual volume. However, the directionally similar changes in end-systolic volume were of lesser proportion than the stroke volume alterations.

\section{REFERENCES}

1. Rapaport, E., B. D. Wiegand, and J. D. Bristow. Estimation of left ventricular residual volume in the dog by a thermodilution method. Circulat. Res. 1962, 11, 803.

2. Bristow, J. D., R. E. Ferguson, F. Mintz, and E. Rapaport. Thermodilution studies of ventricular volume changes due to isoproterenol and bleeding J. appl. Physiol. 1963, 18, 129.

3. Rushmer, R. F. Constancy of stroke volume in ventricular responses to exertion. Amer. J. Physiol. 1959, 196, 745.

4. Warner, H. R., and A. F. Toronto. Regulation of cardiac output through stroke volume. Circulat. Res. 1960, 8, 549.

5. Miller, D. E., W. L. Gleason, R. E. Whalen, J. J. Morris, Jr., and H. D. McIntosh. Effect of ventricular rate on the cardiac output in the dog with chronic heart block. Circulat. Res. 1962, 10, 658.

6. Rushmer, R. F., O. Smith, and D. Franklin. Mechanisms of cardiac control in exercise. Circulat. Res. 1959, 7, 602.

7. Wang, Y., R. J. Marshall, and J. T. Shepherd. Stroke volume in the dog during graded exercise. Circulat. Res. 1960, 8, 558.

8. Chapman, C. B., O. Baker, and J. H. Mitchell. Left ventricular function at rest and during exercise. J. clin. Invest. 1959, 38, 1202.

9. Holt, J. P. Effect of plethora and hemorrhage on left ventricular volume and pressure. Circulat. Res. 1957, 5, 273.

10. Holt, J. P., E. A. Rhode, S. A. Peoples, and H. Kines. Left ventricular function in mammals of greatly different size. Circulat. Res. 1962, 10, 798. 